\title{
Managerial Preferences and Competition in Internal Capital Markets
}

\author{
Uwe-Wilhelm Bloos and Christian Gerhardt*
}

May 31, 2008

\begin{abstract}
It is often argued that managers follow some preference function. The internal capital market literature, for example, most commonly treats managers as empire builders who receive increased private benefits from having more funds under their control. However, recent empirical work (Bertrand and Mullainathan 2003), shows that some managers might prefer to be left to run a limited number of projects. This "enjoying the quiet life" constitutes an alternative type of managerial behavior. In this contribution, we demonstrate how empire building and quiet life preferences work under competition. Our analysis shows that quiet life managers can generally only be motivated by threatening them with competition, while empire builders also value enhanced investment prospects. As we also demonstrate, this leads to different optimal wages in regard to managerial preferences. Additionally we identify two organizational ways to improve managerial incentives. Namely, by letting managers with different investment prospects compete for funds and by altering the ex ante distribution of funds among the department managers. Again, results vary significantly with different managerial preferences.
\end{abstract}

*Goethe University Frankfurt, Finance Department. We thank Ralf Elsas, Guido Friebel, Jan Pieter Krahnen, Christian Laux, Oliver Schellenberger, Conrad Zimmer and seminar participants in Frankfurt for valuable discussions and comments. Mail: bloos@wiwi.uni-frankfurt.de, phone: +49-069-798-22572. 


\section{Introduction}

Firms are run by managers. This is normally true for headquarters as well as the divisions of a firm. An important task when managing a business is to identify and acquire valuable investments. Managers need to put effort into information gathering and processing to determine new investment opportunities. They also need to be compensated for their effort and given incentives to take decisions in the interest of the firm's shareholders. The existence of internal capital allocation now might arguably influence these managerial incentives. In an extreme case, even a perfectly working internal capital market, i.e. ex post optimal resource allocation within a firm, might destroy value because of distorted managerial incentives (Brusco and Panutzi 2005, Laux and Inderst 2005). More precisely, having an internal capital market in place generally influences managers in one of two ways. On the one hand they are potentially willing to put effort into project acquisition because of the chance of obtaining additional capital (being a winner). On the other, managers might be discouraged and less willing to exert effort because of the possibility of being a loser, i.e. having funds taken away from them, which means they might not be able to realize the identified investment opportunities.

It is often argued that in addition to incentive mechanisms and payment, managers also follow some kind of preference function. In addition to monetary incentives managers might value whether they are running one or numerous projects, the structure of the decisions they have to take (firing vs. hiring for example) or how others value their work. These private benefits play a substantial role when examining the possible value that the internal resource allocation may add and also with regard to the question of how an internal capital market alters managerial incentives. In the literature on internal capital markets managers are usually assumed to behave like empire builders, i.e. it is assumed that they derive increasing private benefits with the size or number of the projects that they are running or, equivalently, the funds they are able to invest. These preferences can be rationalized, for example, with increased value given to human capital or managerial concerns 
with regard to prestige or control benefits.

However, there might be alternative preferences which could be plausible. For example Bertrand and Mullainathan (2003) state:

"Our (empirical) results suggest that active empire building may not be the norm and that managers may instead prefer to enjoy the quiet life".

So, employees might prefer not to face new challenges but to be left in charge of tasks they are happy with. This consequently means that managers will not necessarily try to attract as many projects or funds as possible, i.e. managers may not act as empire builders.

These possibly differing managerial preferences and the competition induced by an internal capital allocation give rise to interesting questions which we analyze in this paper. Competition for (scarce) resources is the constitutive issue for the functioning of an internal capital market. To clearly identify the underlying principles in this respect, we explicitly investigate the effects of introducing competition via capital (re-)allocation within a firm by considering both empire building managers and those who prefer the quiet life. Secondly, we address the role of monetary incentives. Are optimal salaries different in regard to managerial preferences? Is their value affected by the presence of an internal capital allocation? These are the questions we analyze.

Empire building (EB) managers have a natural desire to implement more projects and are therefore willing to invest effort to be able to do so. This contrasts sharply with the analysis of managers whose behavior reflects enjoyment of a quiet life (QL). They only react when faced with the threat of losing the current business they are running.

By applying a simple wage scheme we identify the possible role of incentive payment. Wages can be principally used to endorse or override the incentives stemming from private benefit considerations. We show that the concrete optimal wage is generally different in regard to managerial preferences and that competition, in our case internal capital (re)allocation, calls for lower incentive payments. One can also argue that with QL preferences 
managerial incentives are less influenced by their private benefits. For instance managers might only respond to monetary incentives relating to the specific size of business they are in charge of. This can be beneficial for the firm since it makes managerial action more easily assessable, but it might also be more costly to do so, in growing industries for example, where empire building preferences possibly substitute incentive payments.

Extending our analysis and allowing for heterogeneity yields more detailed results on the effects of alternative managerial preferences in a competitive environment. Allowing for different investment prospects, more precisely that one department has a greater chance of aquiring a very good project by investing effort, generally lowers optimal wage payments no matter what the underlying managerial preferences. However, the reasons differ. With QL, only a manager facing worse investment projects ha a greater incentive to execute effort in competition, whereas with EB private benefit considerations increase the incentive of all managers to provide effort, regardless of their investment prospects. This is quite intuitive when one recalls the general effects of competition on the different managers: QL managers are threatened by competition with losing their financial endowments, thus producing more effort when facing "better" competitor seems quite natural; EB managers, value the further enhancement of their investment prospects, meaning that the managers with improved investment prospects are also better motivated to provide effort.

We also run our analysis with different initial financial endowments. Having only very little overall capital in the system, no matter how it is initially allocated, generally aligns incentives, so that QL and EB managers may actually have identical incentives to provide effort. This is due to the fact that they all have the same goals; empire building is simply not possible with very scarce resources. The other extreme appears when capital is available for almost every possible investment opportunity. QL managers then need not fear being expropriated anymore and will consequently not provide any effort at all, while EB managers, on the contrary, will have the highest incentives to exert effort since they will most likely be able to actually implement projects they may have located. Probably, the most interesting result in this section 
is that the managerial incentives may change completely with different initial financial endowments of the departments even at a given overall amount of financing. Altering ex ante financial endowments might be a valuable instrument to provide managers with appropriate incentives via organizational governance.

In summary, we can state that different managerial preferences matter quite significantly in the way managers react to incentives mechanisms. Furthermore, we have identified not only the strategic interaction of incentive payment and managerial preference, but also new organizational instruments to implement the desired equilibrium. Altering, initial financial endowments in the departments can influence the decisions made even without changing the overall amount of capital involved. Additionally, firm restructuring and governance is identified as being a mechanism to induce competition and consequently increase managerial incentives to provide effort.

The rest of the paper is organized in the following way. In section 2 we introduce the model and run the basic analysis with homogeneous projects. We also investigate herein the potential role of incentive payment. Afterwards, in section 3 we extend our analysis to the case of heterogeneity, considering different investment and financial endowments. We conclude with section 4 .

\section{The Model}

Assume a firm with two units of capital that can be invested. Managers who have to identify and realize valuable projects can be employed A manager can influence the success of projects by providing effort, i.e. by the amount of work he personally invests. More precisely manager i can choose between two different levels of effort, $e_{i}=\{e, 0\}$. Providing no effort will certainly lead to a bad project with output $\underline{\pi}$. Conversely, exerting effort $e$ will yield a good project with an output of $\bar{\pi}$ with probability $q$ and a very good project, which actually is modeled as two good projects, i.e. $2 \pi$ with probability $p$. With probability $(1-p-q)$ only a bad project can be realized even with effort provision. Additionally we assume $\bar{\pi}>1>\underline{\pi}$. So, by investing effort a manager can influence the investment opportunities of the firm. The 
manager's personal effort cost are normalized to $e$ (effort invested) or 0 (no effort).

Following Stein (2002), we assume that the firm always invests all internal funds. Furthermore, we implicitly assume throughout the whole analysis that it is always optimal in terms of firm value maximisation that managers actually provide effort, i.e. the "all provide effort" equilibrium is the desired one. Also, when analyzing the case of competition by introducing an internal capital market, reallocation of funds is only applied when a better project, i.e. $\bar{\pi}$ instead of $\underline{\pi}$, can be realized. All players are assumed to be risk neutral.

As previously explained we focus on managerial preferences. We assume that managers realize different private benefits dependant on the projects realized. With no project running, the private benefit of a manager is normalized to zero. Having one project realized may yield positive private benefits of $B_{1}^{\theta}$, running two projects yields $B_{2}^{\theta}$. With $\theta \in\{E B, Q L\}$ we differentiate between the empire building $(E B)$ and quiet life $(Q L)$ managers.

We hereby model the common assumption empire building in the customary way: private benefits increase with the output. So, realizing more projects gives a greater private benefit to the department manager. To keep things simple, we assume that having executed one project (no matter whether bad or good) provides private benefits of $B_{1}^{E B}$ and that having two projects realized, i.e. a very good output, yields $B_{2}^{E B}$. Obviously $B_{1}^{E B}<B_{2}^{E B}$ is needed for empire building.

The second set of preferences we are interested in is what is called enjoying the quiet life. In this case the manager's greater concern is about being in business, i.e. running his department. Therefore the manager receives a private benefit if at least one project is executed. The major difference to $\mathrm{EB}$ is that it is not per se valuable to him to have a second ongoing project. It might actually even be worse having a lot of projects, since that could interfere with "enjoying the quiet life". However, to keep things simple we distinguish QL from EB by stating that the marginal private benefits, in contrast to EB, are zero after a certain point with QL. We therefore assume the following private benefits structure for quiet life managers: $B_{1}^{Q L}=B_{2}^{Q L}=$ $B^{Q L}$. 
With both preference sets we assume that all managers prefer good projects to bad ones as long as they require the same effort from them. Where the relation between $B^{Q L}$ and $B_{1}^{E B}<B_{2}^{E B}$ is concerned one might argue that the private benefits deriving from the first project are the same for all managers irrespective of whether they are empire builders or quiet life managers. Such a view is supported by the manager's acceptance by his company and the the good reputation he enjoys for his first project. However, another line of argument might be that the private benefits of an empire builder from the first project are smaller than those of a quiet life manager, which can be one of the reasons why the former tries to attract more than one project. We keep our modeling setup more general at this point, although we will eventually be able to take into account a more detailed setting of private benefits structures.

\section{The basic trade-offs}

\subsection{One manager - no competition}

We start our analysis by showing the underlying structures of the model in a simple setup without incentive payment. Putting it another way: what decisions will be taken if managers simply earn a flat wage and therefore only try to maximize their private benefits? We start our analysis by assuming that one manager is in charge for the whole firm, i.e. has in principle two units to invest in projects.

A manager who wants to enjoy the quiet life (QL) has no reason to exert any effort if he is always able to implement at least one project, no matter if it is of bad or good quality. So, exactly one bad project will be realized. The manager receives a private benefit of $B^{Q L}>0$ for himself which fulfills the participation constraint normalized to zero.

Let us now turn to the case of an empire building manager. In contrast to the case with QL managers, he has an incentive to provide effort. This is due to the fact that EB managers actually care about the number of projects executed and the opportunity of realizing the higher private benefit $B_{2}^{E B}$. An 
EB manager, who does not face an effort-exerting competitor consequently provides effort if the following constraint is fulfilled:

$$
p\left(B_{2}^{E B}-B_{1}^{E B}\right)>e
$$

To sum up, a QL manager will never provide effort when left on his own to run the firm, an EB on the contrary does exert effort when his expected private benefits from running two projects are high enough, i.e. (1) is fulfilled. These results are not particularly surprising but yield an interesting reference point for the analysis involving competition.

\subsubsection{Two managers - the case of competition}

We now introduce the possibility of hiring a second manager. We basically have in mind that the firm is divided into two departments, each run by a manager. For now we additionally assume that each department is endowed with one unit of capital and that the investment prospects are identical as previously stated. We will look at different endowments and investment opportunities later on. Additionally, we assume that capital may be reallocated between the departments. However, as stated above, this will only be the case when better investment opportunities can be realized, i.e. capital is taken away from a department when it can only realize a bad project and the other department has identified a very good project.

Having split the firm into departments without allowing for re-allocation of funds would not not provide any rationale for a better output to the firm. QL managers still would not provide effort and neither would EB managers, since they were simply not able to realize $B_{2}^{E B}$ due to the lack of funds. However, introducing internal capital allocation with a departamental structure, i.e. capital can be transferred from one division to the other, might also yield a rationale for the department managers to execute effort. This stems from the fact that a manager is under threat of not being able to implement even one project. This will be the case when one division has very good investment prospects, i.e. has found two good projects to invest in but the other division has only come up with bad ones. We look at the 
expected private benefit structure by considering that the expected benefit for a manager in competition, $E\left(B^{\theta}, e_{i}\right)$, depends on the benefit structure and the effort decision. Consequently the following expected private benefits can be realized:

$$
\begin{aligned}
& E\left(B^{\theta}, e\right)=p(1-p-q) B_{2}^{\theta}+[1-2 p(1-p-q)] B_{1}^{\theta}-e \\
& E\left(B^{\theta}, 0\right)=(1-p) B_{1}^{\theta}
\end{aligned}
$$

Proposition 1 "All provide effort" (ee) is a Nash-equilibrium with QL managers if the following constraint is fulfilled:

$$
p(p+q) B^{Q L}>e
$$

Proof. see the appendix.

So, an "all provide effort"-equilibrium becomes possible due to the $\mathrm{QL}$ manager's fear of possibly being expropriated. Consequently, hiring a second manager and having them compete for funds gives QL managers a possible reason to exert effort.

EB managers provide effort in competition when (3) is met:

$$
p(1-p-q)\left(B_{2}^{E B}-B_{1}^{E B}\right)+p(p+q) B_{1}^{E B}>e
$$

In contrast to the case of QL managers, the effects of competition are not obvious with EB managers. As in the case with only one manager, the department managers are attracted by the possibility of potentially realizing $B_{2}^{E B}$ but now are additionally threatened lossing even their initial funding.

Lemma 1 EB managers are indifferent, in terms of expected benefits from effort provision, whether facing a competitor or not, when the following equation applies:

$$
2 B_{1}^{E B}=B_{2}^{E B}
$$

Proof. see the appendix.

Building on Lemma 1 we can therefore differentiate between two cases. 
With $2 B_{1}^{E B}>B_{2}^{E B}$ EB managers realize a greater expected benefit from providing effort when there is a competitor, i.e. (3) is less binding than (1). Therefore being confronted with an effort providing competitor may only induce effort provision in the first place. This is the case when (3) is fulfilled but not (1), i.e. managers only provide effort when, in addition to being able to potentially realize $B_{2}^{E B}$, they are also threatened with losing their funds to a competitor. So, when the potential benefits a manager may realize from two projects are relatively low, i.e. $B_{2}^{E B}<2 B_{1}^{E B}$ threatening them additionally to possibly not being able to realize any benefit may only ensure the (ee) equilibrium. Nevertheless, an EB manager who would provide effort without competition would also do so with competition.

With $2 B_{1}^{E B}<B_{2}^{E B}$ a competitor actually reduces the benefits a manager can expect to gain from effort provision and consequently may even destroy his incentives to provide effort. This is the case when (1) is fulfilled but not (3). One can interprete this finding in the following way: when the potential benefit of additional funds is relatively high, i.e. $2 B_{1}^{E B}>B_{2}^{E B}$, theatening them additionally to lose funds does not provide further motivation, on the contrary. Therefore, when this financing effect, as we may term it, is accompanied by competition, in the sense that it may also be possible to lose one's own funds, a manager is relatively less motivated. In such a scenario and in contrast to one where there is a relatively low expectation of benefits and with QL managers, actually being threatened with competition can be demotivating for EB managers. Introducing competition may therefore negatively affect managerial incentives to provide effort, namely when the expected private benefits from two projects are above a given threshold, i.e. $2 B_{1}^{E B}<B_{2}^{E B}$.

\section{Incentive payment}

We extend our analysis and include the possibility of providing the managers with monetary incentives. In general, monetary incentives are used to induce a desired equilibrium or to put it another way, to destroy an unwanted equilibrium. So, monetary incentives may override or support the incentives 
stemming from private benefits. We are interested in showing the interplay of different private benefits structures and monetary incentives. To keep the analysis simple we assume that incentive contracts can be written on the project output. This leads to forcing contracts, since in the case of a positive output there must have been exertion of effort in the first place. For structural clearness we consider a simple contract where the agent gets a fixed positive wage for a positive output and zero in case of having a bad project realized.

$$
\text { wage }=\left\{\begin{array}{l}
w \text { for } 2 \bar{\pi} \\
w \text { for } \bar{\pi} \\
0 \text { for } \underline{\pi}
\end{array}\right\}
$$

In the case of one manager running the firm, i.e. the possibility of financing a second project, the wage has to cover the effort costs in expectation to ensure effort provision. With QL managers this is the same as without any preferences at all:

$$
\begin{gathered}
(q+p) w-e \geq 0 \\
w \geq \frac{e}{(q+p)}
\end{gathered}
$$

Since a the manager receives the private benefits in either case, they do do play a role and one only has to cover the effort costs. This is different with EB managers: the possibility of receiving a potentially higher private benefit already increases their incentives. The wage one has to grant in the case of a single EB manager amounts to:

$$
\begin{gathered}
p\left(w^{E B}+\left(B_{2}^{E B}-B_{1}^{E B}\right)\right)+q w^{E B} \geq e \\
w^{E B} \geq \frac{e-p\left(B_{2}^{E B}-B_{1}^{E B}\right)}{(q+p)}
\end{gathered}
$$

What changes take place when employing two department managers and introducing internal capital allocation? In the case of QL managers the 
desired "all provide effort" equilibrium can be assured with the following wage contract:

$$
\begin{gathered}
(p+q) w^{Q L}+p(p+q) B^{Q L} \geq e \\
w^{Q L} \geq \frac{e-p(p+q) B^{Q L}}{(p+q)}
\end{gathered}
$$

Similarly the expected optimal wage which will induce the desired "all provide effort" equilibrium with EB managers when internal resource allocation is in place amounts to:

$$
\begin{gathered}
(p+q) w_{c}^{E B}+p(1-p-q) B_{2}^{E B}+\left[(1-2 p(1-p-q)] B_{1}^{E B} \geq e\right. \\
w_{c}^{E B} \geq \frac{e-p(1-p-q)\left(B_{2}^{E B}-B_{1}^{E B}\right)-p(p+q) B_{1}^{E B}}{(p+q)}
\end{gathered}
$$

Considering (5), (7) and (8) we can state that by introducing competition by the possibility of capital re-allocation and facing an effort-exerting competitor, the optimal wage to implement effort provision falls. Additionally, EB managers may be satisfied with lower monetary incentives compared to QL managers, i.e. $w>w^{Q L}>w_{c}^{E B}$.

Taking Lemma 1 into account we can state that $w_{c}^{E B}=w^{E B}$ if $2 B_{1}^{E B}=$ $B_{2}^{E B}$. With relatively low benefits from two projects, i.e. $2 B_{1}^{E B}>B_{2}^{E B}$ providing effort is more valuable in terms of private benefits when actually facing an effort-exerting competitor. Consequently, the optimal wage $w_{c}^{E B}$ is lower than that without competition, i.e. $w^{E B}$. Introducing competition to create fear of loss of funds therefore either lowers the needed wage or ensures the desired (ee) equilibrium in the first place (see also discussion above).

However, this is quite different with relatively high private benefits from additional funds, i.e. $2 B_{1}^{E B}<B_{2}^{E B}$. Facing an effort-providing competitor is in terms of wages at best irrelevant, because private benefits alone already ensure effort provision. If (3) is met but not (1), competition is actually the 
reason for needing a wage to implement the "all provide effort" equilibrium (ee). Without the threat of losing funds but, the possibility of financing a second project, private benefits would ensure effort provision on their own, but with competition an additional wage of $w_{c}^{E B}$ is needed to ensure $(e e)$. Introducing managerial competition when $2 B_{1}^{E B}<B_{2}^{E B}$ may also be costly when the initial manager in charge initially does not provide effort due to private benefits. A wage increase of $\left(w_{c}^{E B}-w^{E B}\right)>0$ must be paid, compared to the case without competition, to induce effort provision by managers in competition. ${ }^{1}$

To sum up, competition for funds in internal capital markets lowers the optimal wage to induce effort provision for QL managers as well as for EB managers with relatively high private benefits from two projects. However, with relatively high benefits from running two projects, i.e. $2 B_{1}^{E B}<B_{2}^{E B}$ a manager can be more cheaply motivated without competition.

\footnotetext{
${ }^{1}$ Note that it may nevertheless be optimal to have two managers in place and exerting effort. However, this would be due to the fact that having two managers running the firm may be advantageous in general and one is willing to pay a wage premium.
} 


\section{$5 \quad$ Heterogeneous projects}

So far we have assumed that when having departments in a firm that they are homogeneous, i.e. they face the same financial constraints and have similar investment opportunities. We now extend our analysis and allow for heterogeneity in two different ways. First, we introduce different investment opportunities and second we analyze the impact of different financial constraints, i.e. ex ante the departments do not face the same restrictions concerning the potential investment capital. We restrict our analysis in both cases to departemental structures and only refer to a firm with one manager in charge when additional insight can be gained by doing so.

\subsection{Different investment opportunities}

We now assume that department $g$ is running its business, for example, in a fast growing market environment and therefore has an increased chance of being able to find a very good project when effort is exerted. We model this by allowing for a very good project, i.e. $2 \bar{\pi}$ with a higher probability, $(p+q)$. With $(1-p-q)$ only a bad project can be realized. However, department $b$ still faces the initial restrictions, i.e. realize $2 \bar{\pi}$ with probability $p$ and $\bar{\pi}$ with probability $q$.

We now need to differentiate between the department managers, the analysis is no longer symmetrical. $E_{j}\left(B^{\theta}, e_{i}\right)$ is now the expected benefit, with $j \in\{g, b\}$. The expected private benefits in regard to effort provision are for the $g$ manager as follows:

$$
\begin{aligned}
& E_{g}\left(B^{\theta}, e\right)=(p+q)(1-p-q) B_{2}^{\theta}+[1-(2 p+q)(1-p-q)] B_{1}^{\theta}-e \\
& E_{g}\left(B^{\theta}, 0\right)=(1-p) B_{1}^{\theta}
\end{aligned}
$$

The expected private benefits for the $b$ manager amount to: 


$$
\begin{aligned}
& E_{b}\left(B^{\theta}, e\right)=p(1-p-q) B_{2}^{\theta}+[1-(2 p+q)(1-p-q)] B_{1}^{\theta}-e \\
& E_{b}\left(B^{\theta}, 0\right)=(1-p-q) B_{1}^{\theta}
\end{aligned}
$$

By evaluating $E_{j}\left(B^{Q L}, e\right)>E_{j}\left(B^{Q L}, 0\right)$ we can show, for QL managers, that the $g$ manager, when faced by a competitor of the initial type, experiences the same incentive constraint now as then, i.e. $p(p+q)>e$ (see (2)). However, the $b$ manager, when confronted with a competitor with better investment perspectives (manager $g$ ), now can expect higher benefits by providing effort, i.e. $(p+q)^{2}>e$.

The difference between homogenous and heteregeneous projects can be demonstrated by the optimal incentive payment changes. While the optimal wage for $\mathrm{QL}$ managers with homogenous projects, $w^{Q L}=\frac{e-p(p+q) B^{Q L}}{(p+q)}$ still applies for the $g$ manager, it is no longer the case for the $b$ manager. With $w_{b}^{Q L} \geq \frac{e-(p+q) B^{Q L}}{(p+q)}$ a lower optimal wage (given positive wages) is sufficient to provide an appropriate incentive to exert effort for the $b$ manager. Again, this is due to the fact that the threat of losing his initial capital unit is greater with an improved competitor, which in turn leads to greater expected effort in the first place and reduces a possible wage payment to implement the "all provide effort" equilibrium.

Thus, we can state that having departments with different investment prospects in place relaxes the constraints on providing managers with appropriate incentives. Empirically such a case can be imagined as a merger of two firms - one with stable investment opportunities and the other a potentially fast-growing firm. Our model predicts that such a merger would create positive incentives for the manager in charge of the stable enterprise. Putting it differently, reorganizing firms is an instrument with the potential to induce competition and provide managers with appropriate incentives to exert effort.

How are the incentives of EB managers affected when there are different investment opportunities in the departments? 
Lemma 2 The private benefits expected from heterogeneous projects under competition are higher for both EB managers than with homogenous projects. In comparison to (3) the $b$ manager has to gain $q(p+q) B_{1}^{E B}$ greater expected benefits from providing effort, the $g$ manager $q(1-p-q)\left(B_{2}^{E B}-\right.$ $\left.B_{1}^{E B}\right)$.

Proof. see the appendix.

Consequently, the managers find effort provision more attractive, or to put it another way, the optimal wages required to induce the "all provide effort" equilibrium can be lower (see discussion for QL managers for similar arguments) $)^{2}$.

While the $b$ manager is threatened with a higher probability of losing his initial capital to an improved competitor, the $g$ manager also values his improved prospects of achieving $B_{2}^{E B}$.

What empirical relevance may we derive from this analysis? At first sight it seems even more desirable than with just QL managers to conduct the merger of a stable with a fast growing firm (see above) because there is now also a competition effect on the $g$ manager.

Putting it all together, grouping firms or departments to compete against each other is an interesting organizational way of providing incentives to managers who follow some preference function. It seems most desirable to group departments with different investment prospects, and especially to let EB managers run departments with good investment prospects and compete against departments with worse prospects run by QL or EB managers, depending on the relation of $B^{Q L}$ to the potential private benefits of an EB manager. With $B^{Q L}$ being relatively low, i.e. $B^{Q L}<B_{1}^{E B}$ it is optimal (see (2) and (3)) to have an EB manager in charge of the department with the worse investment prospects. However, with relatively high private benefits for the QL manager to lose, i.e. $B^{Q L}>B_{2}^{E B}$ one ideally wants a $\mathrm{QL}$ manager to run the department with the worse prospects and providing optimal motivation for both, the QL manager who faces a greater threat of being

\footnotetext{
${ }^{2}$ Note that greater expected private benefits directly lead to lower optimal wages needed. We therefore refrain from showing the actuall effect on wages in the following. One may keep in mind though, that whenever we argue about greater private benefits we ultimately refer to potentially lower wages, i.e. costs of inducing effort provision.
} 
expropriated and the EB manager who values the good investment prospects most. More generally, one could meet asymmetric investment opportunities with different managerial preferences.

\section{Different financial endowments}

We now turn to the second case of heterogeneity. Here we assume that with similar investment opportunities one of the divisions has a higher initial endowment of financial resources. Nevertheless, we stick to the assumption used throughout our analysis, that capital will be only reallocated ex post if there is a better project to realize. In terms of expected benefits we note $E_{k}\left(B^{\theta}, e_{i}\right)$ with $k=\{h, l\}$ standing for the department with high financial resources $(h)$, and $(l)$ for the one with low initial financial resources. We will take a look at different financial structures by adding numbers to $h$ and $l$ representing the actual number of financing units in the particular department, e.g. $h 3$ means that department is the one with more financial resources and that the actual number of financing units is three.

To keep the analysis clear we do not differentiate in regard to $B_{2}^{E B}$ with EB managers but assume that competition is always optimal, i.e. $B_{2}^{E B}$ is large enough (see above).

The first case we analyze is $(h 1 l 0)$. Managers face the following expected benefits:

There is no reason for the $h$ manager to exert effort when the $l$ manager does not also provide effort. More precisely, the situation of a $h$ manager is similar to a single-manager firm. As we have shown a QL manager would never exert effort in such a case However, in contrast to the standard case with two units of funding an Eb also would not provide effort: he due to the lack of funds he simply can never realize $B_{2}^{E B}$ and will therefore also not provide effort due to private benefits. However, no effort at all is not always an equilibrium in a departamental firm since it is optimal for to exert effort with $E_{l 0}\left(B^{\theta}, e\right)=(p+q) B_{1}^{\theta}-e>0$. Facing an effort-exerting competitor, it can also be optimal for $h$ to invest effort: although his possible benefits are 
lower, i.e. $(p+q)^{2} B_{1}^{\theta}-e>0$ resulting from

$E_{h 1}\left(B^{\theta}, e\right)=[(1-(1-p-q))(p+q)] B_{1}^{\theta}-e>E_{h 1}\left(B^{\theta}, 0\right)=(1-p-q) B_{1}^{\theta}$.

Additionally, one needs to account for the incentives of $l$ to provide effort in competition. This is only the case when

$$
E_{l 0}\left(B^{\theta}, e\right)=(1-p-q)(p+q) B_{1}^{\theta}-e>0
$$

Summarizing, we now face a situation in which three equilibria become possible due to private benefit consideration alone: (ee), (00) or effort only by the manager with the low budget. Combining these results we can state that $(e e)$ is possibly an equilibrium if

$$
\min \left[(p+q)^{2} B_{1}^{\theta},(1-p-q)(p+q) B_{1}^{\theta}\right]>e
$$

With effort cost greater than either of the expected benefits, but smaller than $(p+q) B$, only the $l$ manager will invest effort in equilibrium. If $e$ is even greater than this, no one will provide effort. The analysis is independent of the actual managerial preferences.

Consequently we can state, that managerial preferences do only matter in the case of $(h 1 l 0)$ when $B^{Q L} \neq B^{E B}$. Having a total of only one unit of capital to allocate leaves no room for gaining higher benefits $B_{2}^{\theta}$ from expansion, so every manager is only interested in getting the basic benefit $B_{1}^{\theta}$.

We now take a look at a second case with $(h 2 l 0)$. The three equilibria given above are still generally possible. Considering QL managers, nothing changes if $(p+q) B^{Q L}<e$, i.e. no effort at all is still the equilibrium. However, the constraint for $(e e)$ being an equilibrium output changes to

$$
\min \left[p(p+q) B^{Q L}, p(1-p-q) B^{Q L}\right]>e
$$

By comparing (9) and (10) in the case of QL managers one realizes that the effort costs for $(h 2 l 0)$ will always be lower than for $(h 1 l 0)$. This is due to the fact that capital is less scarce and therefore both managers realize higher 
expected private benefits per se. This raises the opportunity cost of exerting effort and makes it generally less profitable.

Now let us take a look at the benefits expected by EB managers in this second case: an equilibrium with competition is given die to private benefits if

$E_{h 2}\left(B^{E B}, e\right)=p B_{2}^{E B}+[(1-p(1-p-q) p)] B_{1}^{E B}-e>E_{h 2}\left(B^{E B}, 0\right)=(1-p) B_{1}^{E B}$

and $E_{l o}\left(B^{E B}, e\right)=p(1-p-q) B_{2}^{E B}+q B_{1}^{E B}-e>0$ are both fulfilled. This leads to the following constraint which is structurally comparable to the one for QL managers:

$$
\min \left[p(1-p-q) B_{2}^{E B}+q B_{1}^{E B}, p\left(B_{2}-(1-p-q) B_{1}^{E B}\right]>e\right.
$$

By assuming a department with three or more units of financing, e.g. the third case with $h 3 l 0$, we get the result that a QL department manager $h$ never has any incentives to provide effort, regardless of the $l$ manager's effort choice: it is always optimal not to exert effort. This is the case because there is no danger for him of ever losing his private benefit $B^{Q L}$ since he will be able to keep at least one unit of financing in any case. Therefore one can treat $l$ as being a single manager without initial funding, i.e. he only invests effort if $(p+q) B^{Q L}>e$.

The situation is slightly more complicated with EB managers. There will also be a dominant strategy for $l$, but it is not necessarily that of not providing effort. The $h$ manager will provide effort if $p\left(B_{2}^{E B}-B_{1}^{E B}\right)>e$, which is exactly the same constraint as with a single-manager firm, i.e. (1). The $l$ manager will not receive any private benefits if he does not provide effort. The incentives for an $l$ manager to exert effort while facing an effortexerting $h$ manager are. $E_{l o}\left(B^{\theta}, e\right)=p(1-p) B_{2}^{E B}+\left(q+p^{2}\right) B_{1}^{E B}-e$. So, $(e e)$ is only an equilibrium if

$$
\min \left[p\left(B_{2}^{E B}-B_{1}^{E B}\right), p(1-p) B_{2}^{E B}+\left(q+p^{2}\right) B_{1}^{E B}\right]>e
$$


We complete our analysis of different financial endowments by taking a look at the case of (h211). In comparison to the basic setup we have one department with an additional unit of capital, and in contrast to every case above, even the $l$ manager possesses ex ante at least one unit of financing. With QL managers the additional unit of capital has no influence on the equilibrium output at all. For every manager the dominant strategy is not to invest effort. This is again due to the fact that there is no real threat of not being able to implement at least one project and realizing the private benefit $B^{Q L}$. Investing effort can therefore never be rational in terms of private benefits since there is nothing to gain from the individual manager's point of view. The picture is not that clear with EB managers. For the $h$ manager, similarly to the $(h 3 l 0)$ case, the decision to provide effort does not depend on the actions of the $l$ manager. Actually he faces exactly the same trade-off and invests effort only if $p\left(B_{2}^{E B}-B_{1}^{E B}\right)>e$. However, the situation changes most significantly for the $l$ manager when he does not invest effort. In contrast to the above case he will now receive the private benefit $B_{1}^{E B}$ because of the initial endowment of one unit of capital. Consequently his incentive to provide effort, i.e. $p(1-p)\left(B_{2}^{E B}-B_{1}^{E B}\right)$ is lower in the case of competition.

To sum up, it would be better for QL managers to receive less ex ante funds while EB managers can generally be motivated with higher initial financing, up to a point. This is due to the fact that QL managers only react to threats while the EB managers also greatly value the possibility of making more investments which they can possibly even finance on their own.

\section{Concluding remarks}

Recent empirical evidence, e.g. Bertrand and Mullainathan (2003) points out that managers might prefer to enjoy the quiet life rather than building empires. By explicitly considering both kinds of managerial preferences we investigated the competition effects induced by internal capital resource allocation. In so doing we identify that changes in the preference function of managers lead to quite different competition effects. While the incentives of 
QL managers to invest effort are induced by the threat of losing their ongoing business, EB managers are also positively motivated by the chance to receive additional capital. These different mechanisms for motivating managers have significant effects on how to use potential instruments to adapt their incentives.

We have identified and discussed two ways of motivating managers through organizational changes. First, one could restructure firms, for example by merging high and low growth divisions. While this might be a quite valuable instrument to induce competition with QL managers, it is even more appealing when EB managers are in charge. This is due to the fact that while for QL managers only the threat of facing stronger competitors matters, EB mangers also value the possibility of potentially investing more funds. Alternatively, headquarters may consider not only reallocating capital ex post but also the ex ante endowments of several divisions to create positive incentives for effort exertion. The use of this instrument is again very different with regard to managerial preferences. While EB managers tend to invest more effort with greater financial endowments, QL managers tend to react to lower financial endowments with greater effort provision. Furthermore, we have shown that optimal incentive payments are generally lower if competition exists but different in regard to managerial preferences.

To the best of our knowledge this is the first paper to address different managerial preferences in a formal organizational model on internal capital markets. Therefore several issues might be worth addressing in future research. For example, the model could be extended to more explicitly address interaction between EB and QL managers within one organization. One can imagine a labor market where managers and firms are matched endogenously. It may also be worthwhile to develop testable implications and provide a more detailed empirical analysis of our results. This in turn may lead to further insights regarding the influence of managerial preferences on competition and eventually on the governance of firms. 


\subsection{Appendix}

Proof. of Proposition 1. A QL department manager will only invest effort if the costs do not exceed the expected (private) benefits, i.e. $E\left(B^{Q L}, e\right)>$ $E\left(B^{Q L}, 0\right)$. This leads to:

$$
\begin{aligned}
p(1-p-q) B_{2}^{\theta}+[1-2 p(1-p-q)] B_{1}^{\theta}-e & >(1-p) B_{1}^{\theta} \\
\left(1-p+p^{2}+q p\right) B^{Q L}-e & >(1-p) B^{Q L} \\
p(p+q) B^{Q L} & >e
\end{aligned}
$$

Proof. of Lemma 1. EB managers do provide effort in equilibrium if they do not face an effort-exerting competitor when the following constraint is fulfilled

$$
\begin{aligned}
p B_{2}^{\theta}+(1-p) B_{1}^{\theta}-e & >B_{1}^{\theta} \\
p\left(B_{2}^{E B}-B_{1}^{E B}\right) & >e
\end{aligned}
$$

Facing an effort-exerting competitor a manager provides effort if $E\left(B^{E B}, e\right)>$ $E\left(B^{E B}, 0\right)$, i.e. the following constraint needs to be fulfilled:

$$
\begin{aligned}
p(1-p-q) B_{2}^{\theta}+[1-2 p(1-p-q)] B_{1}^{\theta}-e & >(1-p) B_{1}^{\theta} \\
p(1-p-q)\left(B_{2}^{E B}-B_{1}^{E B}\right)+p(p+q) B_{1}^{E B} & >e
\end{aligned}
$$

Comparing (1) and (3):

$$
\begin{aligned}
& p\left(B_{2}^{E B}-B_{1}^{E B}\right)=p(1-p-q)\left(B_{2}^{E B}-B_{1}^{E B}\right)+p(p+q) B_{1}^{E B} \\
& p\left(B_{2}^{E B}-B_{1}^{E B}\right)=p\left(B_{2}^{E B}-B_{1}^{E B}\right)+p(p+q) B_{1}^{E B}-p(p+q)\left(B_{2}^{E B}-B_{1}^{E B}\right)
\end{aligned}
$$

The above constraint is fullfilled if $p(p+q) B_{1}^{E B}-p(p+q)\left(B_{2}^{E B}-B_{1}^{E B}\right)=0$. This yields

$$
2 B_{1}^{E B}=B_{2}^{E B}
$$




\section{Proof. of Lemma 2.}

We evaluate $E_{j}\left(B^{E B}, e\right)>E_{j}\left(B^{E B}, 0\right)$. In the case of the $b$ manager the following constraint has to be met to provide appropriate incentives:

$$
\begin{aligned}
p(1-p-q) B_{2}^{E B}+[1-(2 p+q)(1-p-q)] B_{1}^{E B}-e & >(1-p-q) B_{1}^{E B} \\
p(1-p-q)\left(B_{2}^{E B}-B_{1}^{E B}\right)+[1-(1-p-q)-(p+q)(1-p-g)] B_{1}^{E B} & >e \\
p(1-p-q)\left(B_{2}^{E B}-B_{1}^{E B}\right)+[(p+q)-(p+q)(1-p-g)] B_{1}^{E B} & >e \\
p(1-p-q)\left(B_{2}^{E B}-B_{1}^{E B}\right)+(p+q)^{2} B_{1}^{E B} & >e
\end{aligned}
$$

For the $g$ manager the following constraint applies:

$$
\begin{aligned}
(p+q)(1-p-q) B_{2}^{E B}+[1-(2 p+q)(1-p-q)] B_{1}^{E B}-e & >(1-p) B_{1}^{E B} \\
(p+q)(1-p-q)\left(B_{2}^{E B}-B_{1}^{E B}\right)+[1-(1-p)-p(1-p-g)] B_{1}^{E B} & >e \\
(p+q)(1-p-q)\left(B_{2}^{E B}-B_{1}^{E B}\right)+[p(p+g)] B_{1}^{E B} & >e
\end{aligned}
$$




\subsection{References}

1. Bertrand, M. and Mullainathan, S. (2003) "Enjoying the Quiet Life? Corporate Governance and Managerial Preferences", Journal of Political Economy, pp.1043-1075.

2. Bertrand, M. and Mullainathan, S. (2004) "Cash Flow and Investment Project Outcomes: Evidence from Bidding on Oil and Gas Leases", Working Paper.

3. Brusco, S. and Panunzi, F. (2005) "Reallocation of Corporate Resources and Managerial Incentives in Internal Capital Markets", European Economic Review, pp. 659-681.

4. De Motta, A. (2003) "Managerial Incentives and Internal Capital Markets", Journal of Finance, pp. 1193-1220.

5. Inderst, R. and Laux, C. (2005) "Incentives in internal capital markets: capital constraints, competition, and investment opportunities", RAND Journal of Economics, pp. 215-228.

6. Rajan, R., Servaes, H. and Zingales, L. (2000) "The Cost of Diversity: The Diversification Discount and Inefficient Investment", Journal of Finance, pp. 35-80.

7. Scharfstein, D. S. and Stein, J. C. (2000) "The Dark Side of Internal Capital Markets: Divisional Rent-Seeking and Inefficient Investment", Journal of Finance, pp. 2537-2564.

8. Stein, J. C. (1997) "Internal Capital Markets and the Competition for Corporate Resources", Journal of Finance, pp. 111-133.

9. Stein, J. C. (2002) "Information Production and Capital Allocation": Decentralized versus Hierarchical Firms, Journal of Finance, pp. 18911921. 